interesting chapter in as much as it examines in detail ethical conflicts that might confront a counsellor in his or her practice. The discussion is based on the four principles of autonomy, beneficence, non-maleficence and justice. Although this chapter presents an in-depth examination of those ethical issues of which all those involved in counselling should be aware, it does not focus specifically on any particular issues that might be more relevant to a counsellor working in general practice. A discussion of the four principles with specific reference to a counsellor working as a member of a primary care team might have been useful in the context of the book's focus.

The final chapter looks to the future of counselling in general practice and at its funding, the involvement of Family Health Service Authorities, evaluation, standards and counsellors' training needs.

The message of the book is that counselling in general practice should be made more accessible to people in order that they may be appropriately enabled to deal with their problems and to live more resourcefully.

ROZY VAN MESDAG Counsellor,

London

\section{Torture and its}

\section{consequences: current treatment approaches}

\author{
Edited by Metin Başoğlu, \\ Cambridge, Cambridge University \\ Press, 1992, 517 pages, £55.00.
}

Medical science has been slow to recognise the special needs of victims of torture but over the past decade or so there has been increasing awareness; papers have appeared and treatment and rehabilitation units have been set up round the world, some in countries which have experienced torture and some in countries which have accepted torture survivors as refugees. The effects of torture have often been equated with various other forms of trauma, such as those arising from war, natural or manmade disasters, and child or sexual abuse. While all of these conditions share many features, (for instance, child and sex abuse are deliberate acts degrading another and may be ongoing), each has its own specificity, and it would be wrong to lump them all together.

Should there then be a new specialty, dealing only with the diagnosis and treatment of torture victims? This question is put by the editor in the introduction to this book, bringing in the unpleasant-sounding neologism 'torturology'. Much space is given to consideration of post-traumatic stress disorder and most contributors agree that, although is is a valuable diagnosis, since it is recognised in major international classifications, and rightly demonstrates that very diverse causes of stress produce similar limited symptom patterns, it does not adequately cover the findings in torture survivors.

Since the editor and most of the contributors are psychiatrists or psychologists, there is a strong psychiatric slant in the book, many of the authors rightly pointing to the need for future research. One useful chapter on physical after-effects and chapters on the psycho-social consequences of torture and on its psycho-biological effects redress the balance somewhat. There are useful chapters on survivors of the holocaust and on the long-term fate of exprisoners of war. The predominant flavour of the book is of western experts writing from the safe perspective of their own country. This is helpfully offset by chapters from experts working in some of the countries which have experienced torture, namely, Argentina, South Africa, Pakistan and the Philippines. These, because the authors are able to convey their personal involvement, are the most compelling contributions of all. One aspect which seems to have been given less than its fair share of space is the psychosomatic effects of torture, and there is no mention at all of some, notably stress ulcer or hyperventilation. The origin of these effects needs to be detected but is often missed by non-specialists such as general practitioners or hospital doctors.

When it comes to treatment of the psychological after-effects, there is no consensus. Some contributors consider that mentioning the traumas of the past will trigger uncontrollable emotional distress, while the behaviourists regard recounting of events as an essential part of the therapy.

Altogether, this is a valuable discussion of current research and management of torture victims, of most use to those working in the field. The subject seems not to have been dealt with previously in so comprehensive a volume.

DUNCAN FORREST $\Rightarrow$

Medical Foundation for the Care of $\stackrel{\text { P }}{+}$ Victims of Torture, London. Medical Group, Amnesty International, British Section.

\section{Euthanasia and other medical decisions concerning the end of life}

P J van der Maas, J J M van Delden, L Pijnenborg, Amsterdam, Elsevier, $1992,262+x v i i$ pages $\$ 160.50$.

This investigation was completed in 윽 1991, and a variety of interpretations $\vec{\sim}$ of its findings have been in circulation. $\overparen{D}$ So it is useful now to have the full account in English. This helps to temper some of the wilder claims and counter-claims about the practice of euthanasia in the Netherlands. The $\vec{\theta}$ book is based on interviews with ove 400 Dutch physicians, who also co laborated in a prospective study, a on data related to a sample of around 8,500 death certificates.

It found that in $1990,2,300$ or 1.8 per cent of all deaths in the $\mathbb{D}$ Netherlands could be classified as euthanasia ("purposeful acting to terminate life by someone other than the person concerned upon the request of the latter') and 400 or 0.3 per cent as assisted suicide. The lives of $1,000 \overline{3}$ patients $(0.8$ per cent of all deaths) were terminated without explicit $\frac{\sigma}{3}$ request; and in the case of 22,500 . others $(17.5$ per cent) pain and/or 0 symptoms were alleviated, taking into account a probable shortening of life. 음 Very few patients in any of these groups were likely to have survived for more than a further six months, and many had only days or hours to live. $N$ Almost all significant shortening of life was in the further category of decisions to withhold or withdraw treatment, which could equally be described as decisions not to prolongeo life by disproportionate means.

On initial reports of this investiga- $\$$ tion, critics made much of the $1,000^{\circ}$ 'life terminating acts without request'. $\bar{O}$ The book suggests that over half of the $\frac{\vec{D}}{\mathrm{D}}$ patients involved had earlier indicated $\stackrel{\rho}{\vec{P}}$ that they would have wanted their $\stackrel{\mathbb{Q}}{2}$ lives ended in these circumstances. Almost all of those whose wishes were not known were terminally ill, suffer- 